\title{
Associations between fluid removal and number of B-lines, peak early mitral inflow wave velocity, and inferior vena cava dimensions in hemodialysis patients
}

\author{
Kazuo Kimura ${ }^{1,2}$, Katsuya Kajimoto $^{3}$, Shigeru Otsubo ${ }^{1,4^{*}}$, Takashi Akiba $^{2}$ and Kosaku Nitta ${ }^{1}$
}

\begin{abstract}
Background: The inferior vena cava (IVC) dimensions represent the right ventricular preload, whereas the peak early mitral inflow wave velocity (peak E-velocity) represents the left ventricular preload. On the other hand, B-lines represent extravascular lung water. The aim of this study was to evaluate possible acute changes in the IVC dimensions, peak E-velocity, and number of B-lines during hemodialysis therapy.

Methods: A total of 55 consecutive patients receiving maintenance hemodialysis were enrolled in this study. We performed echo-graphic examinations at three time points (just after the start, during the middle, and just before the end of the hemodialysis therapy). We then investigated the changes in the IVC dimensions, peak E-velocity, and number of B-lines.

Results: The peak E-velocity decreased from $80 \pm 26 \mathrm{~cm} / \mathrm{s}$ at the start of the therapy to $58 \pm 22 \mathrm{~cm} / \mathrm{s}$ during the middle and $51 \pm 21 \mathrm{~cm} / \mathrm{s}$ at the end of the therapy. The IVC dimensions also decreased from $15 \pm 4 \mathrm{~mm}$ at the start of the therapy to $12 \pm 3 \mathrm{~mm}$ during the middle and $11 \pm 3 \mathrm{~mm}$ at the end of the therapy. The number of B-lines also decreased from $12 \pm 5$ at the start of the therapy to $9 \pm 4$ during the middle and $5 \pm 3$ at the end of the therapy. The changes in the peak E-velocity and IVC dimensions were significantly greater during the first half of the dialysis period than during the second half of the dialysis period $(P<0.0001$ and $P<0.0001$, respectively). On the other hand, the changes in the number of B-lines during these periods were significantly smaller during the first half of the dialysis period than during the second half of the dialysis period $(P=0.0016)$.

Conclusions: We showed that the peak E-velocity and the IVC dimensions were reduced mainly during the first half of the dialysis period, while the number of B-lines showed a significant decrease mainly during the last half of the dialysis period. Even if the IVC dimensions are reduced sufficiently, caution is needed as lung congestion may still exist.
\end{abstract}

Keywords: B-lines, Early diastolic filling velocity, Early diastolic filling wave, Hemodialysis, Inferior vena cava, Lung ultrasound

\footnotetext{
* Correspondence: sotsubo@hb.tp1.jp

'Department of Medicine, Kidney Center, Tokyo Women's Medical University,

Tokyo, Japan

${ }^{4}$ Department of Blood Purification, Tohto Sangenjaya Clinic, 2-13-2 Taishido,

Setagaya-ku, Tokyo 154-0004, Japan

Full list of author information is available at the end of the article
} 


\section{Background}

Chronic fluid overloading frequently occurs in hemodialysis patients, so volume assessment during hemodialysis is a primary, and often challenging, goal of nephrologists. Volume overload is directly associated with hypertension, increased arterial stiffness, left ventricular hypertrophy, heart failure, and ultimately higher rates of mortality and morbidity [1].

Lung ultrasound has recently been shown to be a useful, noninvasive technique for the assessment of extravascular lung water [2]. The most commonly observed finding was a comet tail artifact fanning out from the lung-wall interface and spreading upwards to the edge of the screen, previously named a "B-line" [3]. In patients with heart failure, the number of B-lines was correlated with the degree of extravascular lung water $[4,5]$. Lung ultrasound is also reportedly useful for the accurate evaluation of dry weight and fluid status in hemodialysis patients $[2,6,7]$.

The inferior vena cava (IVC) dimensions represent the right ventricular preload [8], whereas the peak early mitral inflow wave velocity (peak E-velocity) represents the left ventricular preload $[9,10]$. On the other hand, B-lines represent extravascular lung water. The aim of this study was to evaluate possible acute changes in IVC dimensions, peak E-velocity, and B-lines during hemodialysis therapy.

\section{Methods}

A total of 55 patients receiving maintenance hemodialysis at Sekikawa Hospital and in whom more than $1 \mathrm{~kg}$ was removed during hemodialysis were enrolled in this study. Patients with lung disease or chest injury were excluded from this study.

Clinical data including age, sex, duration of hemodialysis therapy, presence of diabetes mellitus and/or hypertension and/or dyslipidemia complications, and the results of biological examinations were collected from the patients' clinical records. Hypertension was defined as a systolic blood pressure of $140 \mathrm{mmHg}$ or higher, a diastolic blood pressure of $90 \mathrm{mmHg}$ or higher, and/or the current use of antihypertensive drugs. Diabetes mellitus was defined as a fasting glucose level $\geq 126 \mathrm{mg} / \mathrm{dL}$, a nonfasting glucose level $\geq 200 \mathrm{mg} / \mathrm{dL}$, or the use of medication. Dyslipidemia was defined as a low-density lipoprotein cholesterol level $\geq 140 \mathrm{mg} / \mathrm{dL}$, a high-density lipoprotein cholesterol level $<40 \mathrm{mg} / \mathrm{dL}$, a triglyceride level $\geq 150 \mathrm{mg} / \mathrm{dL}$, or the use of medication.

A peripheral blood sample was obtained before hemodialysis during the first session of the week. The serum N-terminal pro-brain natriuretic peptide (NTproBNP) level in the pre-dialysis blood sample was measured using an electrochemiluminescence immunoassay on an Elecsys platform (Roche, Basel, Switzerland).

A lung ultrasound examination was performed during the first session of the week (at the same time as the peripheral blood sample preparation) using Vscan ${ }^{\circ}$ (GE Healthcare, Japan), which is a hand-held ultrasound device with a wide-bandwidth phased-array probe $(1.7-3.5 \mathrm{MHz})[11,12]$. Bilateral scanning of the anterior and lateral chest walls was performed with the patient in a supine position. An intercostal scan with a maximum extension of the visual pleural line was performed. The chest wall was divided into eight areas (two anterior and two lateral areas per side), and one scan was obtained for each area [13]. The anterior zone of the chest wall was designated from the sternum to the anterior axillary line and was then divided into upper and lower halves (from the clavicle to the third intercostal spaces and from the third space to the diaphragm). The lateral zone was positioned from the anterior axillary line to the posterior axillary line and was also divided into the upper and lower halves. The investigators attempted to detect comet tail artifacts fanning out from the lung-wall interface and spreading to the edge of the screen, which were previously named as B-lines (Fig. 1) [5, 6]. The total number of B-lines was estimated. Echocardiographic measurements were obtained at the same time, and the IVC dimensions and peak E-velocity were estimated. We performed echographic examinations three times (just after the start, just in the middle (for example, $2 \mathrm{~h}$ after the start of hemodialysis therapy if the treatment time is $4 \mathrm{~h}$ ), and just before the end of the hemodialysis therapy). We then investigated the changes in the IVC dimensions, peak E-velocity, and B-lines. This study was conducted in accordance with the principles of the Declaration of Helsinki and was permitted by the research ethics committee of Sekikawa Hospital (Approved No. H2705). The data were expressed as the means $\pm \mathrm{SD}$ or median (interquartile range, IQR). Paired $t$ tests were used to examine changes in the variables.

All the statistical calculations were performed using JMP 5.1 software. $P$ values less than 0.05 were considered statistically significant.

\section{Results}

The patient background characteristics are shown in Table 1 . The mean age was $75 \pm 11$ years. Elderly patients were common in this study. Diabetic nephropathy was the major cause of end-stage kidney disease. Hypertension, diabetes mellitus, and dyslipidemia were present in $89.1,47.3$, and $16.4 \%$ of the study participants, respectively. The results of the biochemistry analyses, 


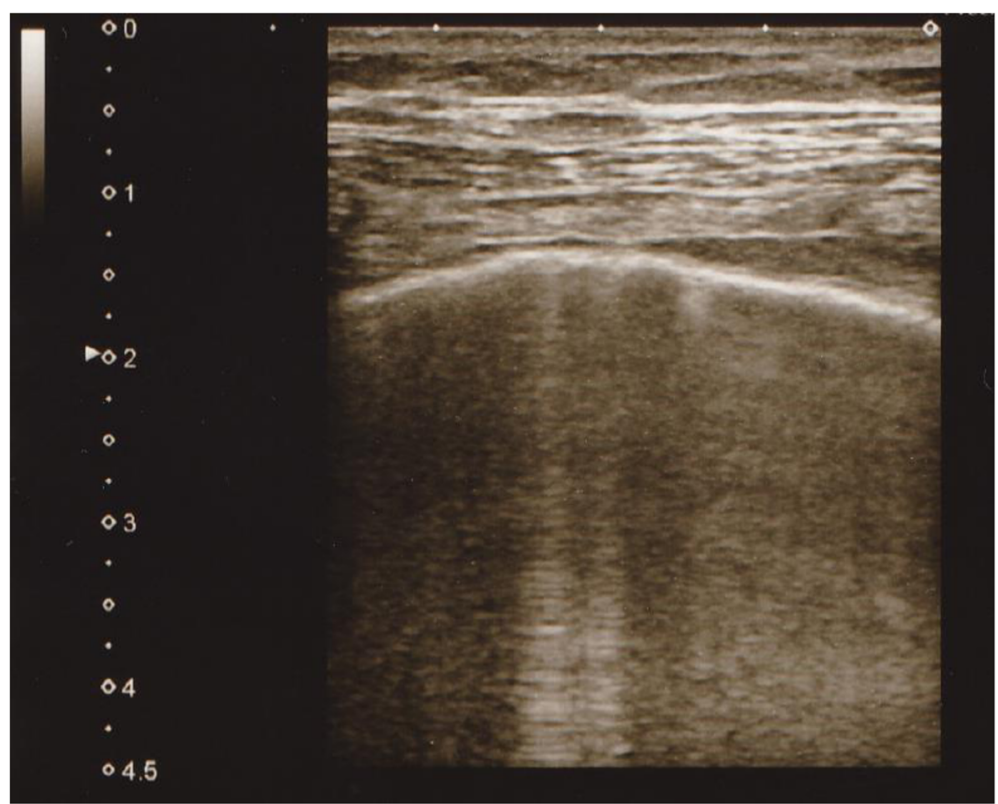

Fig. 1 B-lines-comet tail artifacts fanning out from the lung-wall interface and spreading upwards to the edge of the screen

Table 1 Background characteristics of the study participants

\begin{tabular}{ll}
\hline Characteristic & Quantity \\
\hline Gender (M/F) & $26 / 29$ \\
Age (year) & $75 \pm 11$ \\
Duration of HD (year) & $6.5 \pm 8.8$ \\
Primary cause of ESKD, $n$ (\%) & \\
$\quad$ Chronic glomerulonephritis & $8(14.5)$ \\
Diabetic nephropathy & $26(47.3)$ \\
Nephrosclerosis & $13(23.6)$ \\
$\quad$ Unknown and others & $8(14.5)$ \\
Hypertention, $n$ (\%) & $49(89.1)$ \\
Diabetes mellitus, $n$ (\%) & $26(47.3)$ \\
Dyslipidemia, $n$ (\%) & $9(16.4)$ \\
Atrial fibrillation, $n$ (\%) & $8(14.5)$ \\
History of PCl or CABG & $8(14.5)$ \\
History of valve replacement & $2(3.6)^{\mathrm{a}}$ \\
Body weight (kg) & $52.0 \pm 10.9$ \\
Systolic blood pressure (mmHg) & $147 \pm 25$ \\
Diastolic blood pressure (mmHg) & $74 \pm 15$ \\
Heart rate (beat/min) & $75 \pm 13$ \\
\hline
\end{tabular}

Mean $\pm S D$, median (interquartile range)

$H D$ hemodialysis, ESKD end-stage kidney disease, $P C l$ percutaneous coronary intervention, $C A B G$ coronary artery bypass graft

${ }^{\mathrm{a}}$ Both patients underwent aortic valve replacement therapy including the NT-proBNP level, are shown in Table 2. The serum albumin level was relatively low $(3.1 \pm 0.5 \mathrm{~g} /$ $\mathrm{dL}$ ), and the serum NT-proBNP level was relatively high $(13,650[4901-35,825] \mathrm{pg} / \mathrm{mL})$ among the study participants. Table 3 shows the background characteristics of the echocardiographic indices. The mean ejection fraction was $60 \% \pm 12 \%$.

The treatment time was $3.7 \pm 0.4 \mathrm{~h}$, and $2.1 \pm 0.9 \mathrm{~kg}$ water was removed. The blood pressure and pulse rate were $146 \pm 25 / 74 \pm 15 \mathrm{mmHg}$ and $75 \pm 13$ beats $/ \mathrm{min}$ at the first echo examination, $134 \pm 24 / 72 \pm 14 \mathrm{mmHg}$ and $72 \pm 16$ beats $/ \mathrm{min}$ at the second, $132 \pm 27 / 73 \pm 16 \mathrm{mmHg}$ and $73 \pm 15$ beats/min at the final examination. Table 4 shows the changes in the echocardiographic indices. The peak E-velocity decreased from $80 \pm 26 \mathrm{~cm} / \mathrm{s}$ at the start of the therapy to $58 \pm 22 \mathrm{~cm} / \mathrm{s}$ during the middle and 51 $\pm 21 \mathrm{~cm} / \mathrm{s}$ at the end of the therapy. The IVC dimensions also decreased from $15 \pm 4 \mathrm{~mm}$ at the start of the

Table 2 Background characteristics of laboratory data

\begin{tabular}{ll}
\hline Characteristic & Quantity \\
\hline Albumin $(\mathrm{g} / \mathrm{dL})$ & $3.1 \pm 0.5$ \\
Urea nitrogen $(\mathrm{mg} / \mathrm{dL})$ & $50.2 \pm 18.3$ \\
Creatinine $(\mathrm{mg} / \mathrm{dL})$ & $7.36 \pm 2.56$ \\
Sodium $(\mathrm{mEq} / \mathrm{L})$ & $137 \pm 4$ \\
C-reactive protein $(\mathrm{mg} / \mathrm{dL})$ & $0.27(0.10-0.86)$ \\
Hemoglobin $(\mathrm{g} / \mathrm{dL})$ & $10.4 \pm 1.2$ \\
NT-proBNP $(\mathrm{pg} / \mathrm{mL})$ & $13,650(4901-35,825)$
\end{tabular}

Mean \pm SD, median (interquartile range)

$N T$-proBNP N-terminal pro-brain natriuretic peptide 
Table 3 Background characteristics of the echocardiographic indices

\begin{tabular}{ll}
\hline Parameter & Value \\
\hline LVDd (mm) & $46 \pm 6$ \\
LVDs $(\mathrm{mm})$ & $31 \pm 7$ \\
EF $(\%)$ & $60 \pm 14$ \\
Max WT $(\mathrm{mm})$ & $12 \pm 2$ \\
\hline
\end{tabular}

Mean \pm SD

LVDd left ventricular diastolic diameter, LVDs left ventricular systolic diameter, $E F$ ejection fraction, $W T$ wall thickness

therapy to $12 \pm 3 \mathrm{~mm}$ during the middle and $11 \pm 3 \mathrm{~mm}$ at the end of the therapy. The number of B-lines also decreased from $12 \pm 5$ at the start of the therapy to $9 \pm 4$ during the middle and $5 \pm 3$ at the end of the therapy (also shown in Fig. 2).

Table 5 shows a comparison of the changes in values between the middle to pre-dialysis periods and the post-dialysis to middle periods. The changes in the peak E-velocity and the IVC dimensions were significantly greater during the first half of the dialysis period than during the second half of the dialysis period $(P<0.0001$ and $P<0.0001$, respectively). On the other hand, the changes in the B-lines between these periods was significantly smaller during the first half of the dialysis period than during the second half of the dialysis period $(P=0.0016)$.

Figure 3 shows a representative case in this study. The peak E-velocity and IVC dimensions decreased mainly during the first half of the dialysis period, while the number of B-lines decreased steadily throughout the dialysis period.

\section{Discussion}

We found that the peak E-velocity and IVC dimensions decreased significantly mainly during the first half of the dialysis period, while the number of B-lines decreased significantly mainly during the last half of the dialysis period.

Lung ultrasound is a novel, well-validated technique that allows reliable estimates of lung water in clinical practice [14]. B-lines can be evaluated anywhere (including extreme environmental conditions using pocket-sized instruments to detect high-altitude pulmonary edema), anytime (during dialysis), by anyone (even a novice sonographer after $1 \mathrm{~h}$ of training), and on anybody (since the chest acoustic window usually remains patent even when an echocardiography is not feasible) [15].

The peak E-velocity represents the flow to the left ventricle, which occurs after the left ventricle diastole, reflecting the preload status $[9,10]$. Ultrafiltration during hemodialysis results in a marked reduction in the circulating blood volume with a concomitant reduction in the left atrial pressure. Acharya et al. examined the parameters of left ventricular diastolic function among hemodialysis patients [16]. A comparison of the pre- and post-hemodialysis peak mitral $\mathrm{E}$ and $\mathrm{A}$ velocities showed a decrease in E-velocity, whereas the change in A velocity was not significant. Ultrafiltration during hemodialysis causes a rapid reduction in the preload, resulting in decreased early left ventricular diastolic filling without a change in the atrial phase of filling, thereby reducing the calculated E/A ratio [16]. We confirmed the change in the peak E-velocity and revealed a greater reduction during the first half of the dialysis period than during the second half of the dialysis period. We also confirmed that E/A ratio was declined during the hemodialysis therapy.

The IVC dimensions are strongly associated with the right atrial pressure and blood volume and therefore reflect the intravascular volume accurately.

Table 4 Changes in echocardiographic indices

\begin{tabular}{|c|c|c|c|c|c|}
\hline Parameter & Just after the start (1st) & Middle (2nd) & Just before the end (3rd) & $P$ (1st vs 2nd) & $P$ (2nd vs 3rd) \\
\hline $\mathrm{E}(\mathrm{cm} / \mathrm{s})$ & $80 \pm 26$ & $58 \pm 22$ & $51 \pm 21$ & $<0.0001$ & $<0.0001$ \\
\hline $\mathrm{A}(\mathrm{cm} / \mathrm{s})^{\mathrm{a}}$ & $87 \pm 30$ & $77 \pm 22$ & $72 \pm 20$ & 0.0006 & 0.0039 \\
\hline E/A & $0.95 \pm 0.39$ & $0.72 \pm 0.26$ & $0.68 \pm 0.26$ & $<0.0001$ & 0.0083 \\
\hline Dct (msec) & $255 \pm 97$ & $271 \pm 92$ & $281 \pm 94$ & Ns & Ns \\
\hline $\mathrm{Ea}(\mathrm{cm} / \mathrm{s})$ & $5.3 \pm 1.7$ & $5.4 \pm 1.6$ & $5.6 \pm 1.6$ & 0.0459 & Ns \\
\hline TRPG $(\mathrm{mmHg})$ & $4.5 \pm 12.4$ & $2.8 \pm 9.5$ & $2.4 \pm 9.0$ & 0.0237 & Ns \\
\hline IVC-ex (mm) & $15 \pm 4$ & $12 \pm 3$ & $11 \pm 3$ & $<0.0001$ & $<0.0001$ \\
\hline IVC-in (mm) & $11 \pm 5$ & $5 \pm 3$ & $3 \pm 3$ & $<0.0001$ & $<0.0001$ \\
\hline IVC collapsibility (\%) & $31 \pm 19$ & $61 \pm 18$ & $74 \pm 20$ & $<0.0001$ & $<0.0001$ \\
\hline B-lines & $12 \pm 5$ & $9 \pm 4$ & $5 \pm 3$ & $<0.0001$ & $<0.0001$ \\
\hline
\end{tabular}

Mean \pm SD

$E$ peak early diastolic filling velocity, $A$ peak Atrial filling velocity, Dct deceleration time, Ea lateral early diastolic mitral annular velocities, TRPG tricuspid regurgitation pressure gradient, IVC inferior vena cava dimensions, ex exhalation, in inspiration

${ }^{a}$ Exclude eight atrial fibrillation 

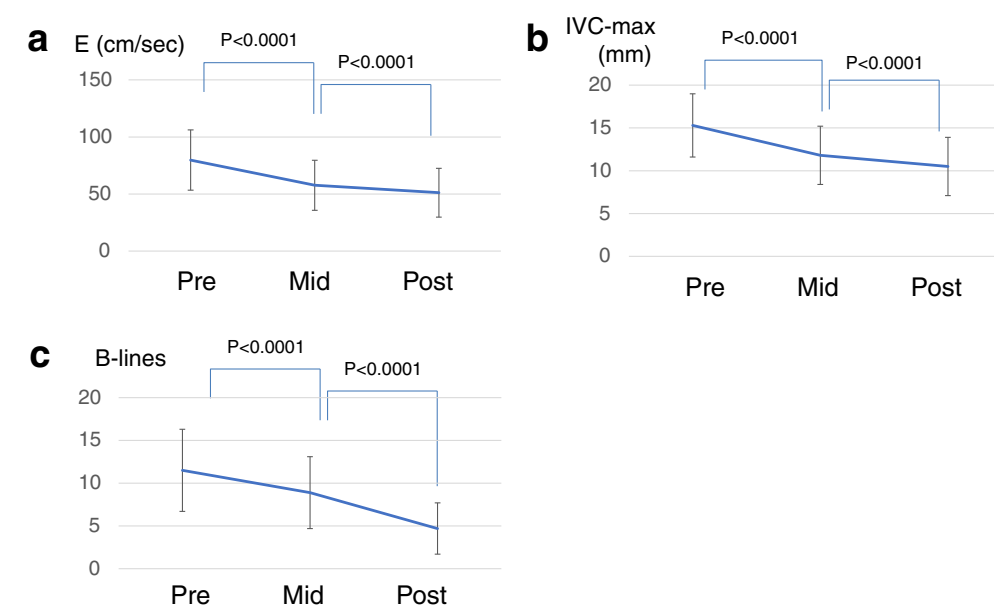

Fig. 2 Changes in echocardiographic indices. a Changes of peak E-velocity. b Changes of IVC dimensions. c Changes of B-lines. Peak E-velocity peak early mitral inflow wave velocity, IVC inferior vena cava

However, a major limitation of IVC dimension measurements is that ultrasound might not be sensitive enough to detect rapid volume decreases in HD patients because it reflects the intravascular filling grade $[17,18]$. Indeed, similar to the change in the peak E-velocity, we showed that the IVC dimensions decreased mainly during the first half of the dialysis period, while the B-lines, which represent lung congestion, decreased significantly mainly during the last half of the dialysis period. This finding may be largely dependent on the time lag in plasma refilling. Alexiadis et al. reported that the number of B-lines has better discriminative power for predicting over- and underhydration, as determined by the IVC dimensions [2]. Mallamaci et al. suggested that the detection of extracellular water in the lung compartment constitutes a reliable tool for the prognosis of overhydration and is thus amenable to intervention [19]. So, we should be careful that even if the IVC dimensions are sufficiently reduced, lung congestion may still exist and should be treated.

Our study had some limitations. The sample size was relatively small, and the study was performed at a single institution. Activities of daily living of some patients

Table 5 Comparison of the changes in values between the middle to pre-dialysis periods and the post-dialysis to middle periods

\begin{tabular}{llll}
\hline & 2nd-1st & 3rd-2nd & $P$ value \\
\hline$\Delta \mathrm{E}(\mathrm{cm} / \mathrm{s})$ & $-23 \pm 14$ & $-7 \pm 6$ & $<0.0001$ \\
$\Delta \mathrm{IVC}$-ex $(\mathrm{mm})$ & $-4 \pm 3$ & $-1 \pm 2$ & $<0.0001$ \\
$\Delta$ B-lines & $-3 \pm 3$ & $-4 \pm 2$ & 0.0016 \\
\hline
\end{tabular}

Mean \pm SD

1st just after the start, 2nd middle, 3rd just before the end, $E$ peak early diastolic filling velocity, IVC inferior vena cava dimensions, ex exhalation were poor, so we could not examine height of patients. In addition, the limitations of lung ultrasound are essentially patient-dependent. Obese patients may be more difficult to examine because of the thickness of their ribcages and soft tissues. Furthermore, in this analysis, we performed ultrasound examinations only at the end of the hemodialysis therapy. However, it has been suggested that post-dialysis assessments should ideally occur $2 \mathrm{~h}$ after hemodialysis because of the reequilibration of interstitial and intravascular compartments $[20,21]$. Accordingly, further study is needed to evaluate the relationship between fluid removal and the timing of post-dialysis assessments in hemodialysis patients. Factors which could affect the change of the number of B-lines are important for the clinician. The change of B-lines was negatively related to the number of B-lines at the start of the hemodialysis therapy $\left(r^{2}=\right.$ $0.609, P<0.0001$, data not shown). We should examine the association between the change of the number of $\mathrm{B}$-lines and various factor under the same number of Blines at the start of hemodialysis therapy, but we could not because of the small number of study participant. Even though ultrasound of extravascular lung water is reported as a new standard for pulmonary congestion [15], there is still no gold standard of examination to evaluate excess body water. In this study, we could not show other possible parameters such as chest X-ray or bioimpedance spectroscopy. Accordingly, further study will be needed to clarify this finding. Another limitation of this study is that we could not show the optimal number of B-lines after hemodialysis therapy. B-lines within physiological range may be present. We have previously reported that B-lines are associated with low serum level of albumin and low body weight [6]. So, optimal number of B-lines may be different among hemodialysis patients. 

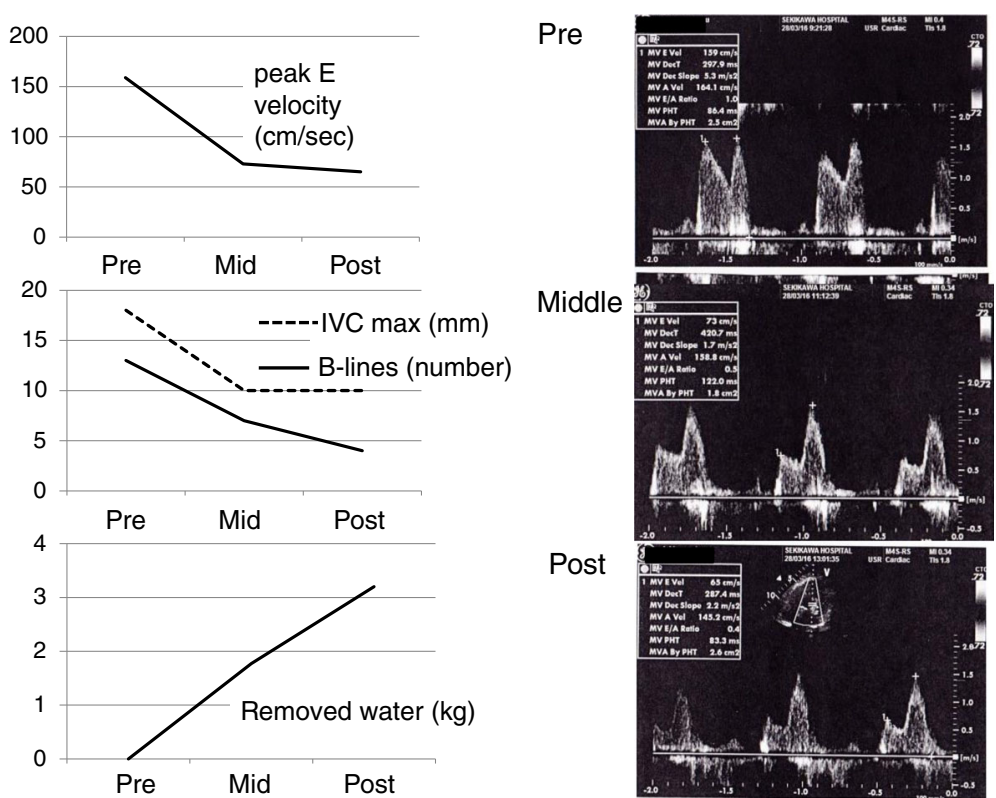

Fig. 3 Case of a 71 year-old female, chronic kidney disease 5D (due to diabetic nephritis). Change of peak E-velocity, IVC dimensions, and B-lines were shown. B-mode images of actual $\mathrm{E}$ and $\mathrm{A}$ velocity were also shown. Remarkable decrease of peak E-velocity was observed compared with peak atrial filling velocity. Peak E-velocity peak early mitral inflow wave velocity, IVC inferior vena cava

\section{Conclusions}

We showed that the peak E-velocity and IVC dimensions were reduced mainly during the first half of the dialysis period, while the number of B-lines decreased significantly mainly during the last half of the dialysis period. Even if the IVC dimensions are sufficiently reduced, caution is required as lung congestion may still exist.

\section{Abbreviations}

E-velocity: Peak early mitral inflow wave velocity; IVC: Inferior vena cava peak; NT-proBNP: N-terminal pro-brain natriuretic peptide

\section{Acknowledgements}

The authors are very grateful to the dialysis staff who understood the clinical importance of this study and who provided high-quality data in Sekikawa Hospital.

\section{Funding}

This study was not supported by any grants or funding.

\section{Availability of data and materials}

The datasets during and/or analyzed during the current study are available from the corresponding author on reasonable request.

\section{Authors' contributions}

KK planned the study, searched the literature, assessed the studies, extracted the data, analyzed the data, and prepared the article. KK and SO searched the literature, assessed the studies, and assisted in the article preparation. KK performed the lung echo. KN and TA assisted in the article preparation. All authors read and approved the final manuscript.

\section{Ethics approval and consent to participate}

This study was approved by the research ethics committee of Sekikawa Hospital (Approved No. H2705) and was conducted under the Declaration of Helsinki.
Consent for publication

Not applicable

\section{Competing interests}

The authors declare that they have no competing interests.

\section{Publisher's Note}

Springer Nature remains neutral with regard to jurisdictional claims in published maps and institutional affiliations.

\section{Author details}

'Department of Medicine, Kidney Center, Tokyo Women's Medical University, Tokyo, Japan. ${ }^{2}$ Department of Nephrology, Sekikawa Hospital, Tokyo, Japan. ${ }^{3}$ Department of Cardiology, Sekikawa Hospital, Tokyo, Japan. ${ }^{4}$ Department of Blood Purification, Tohto Sangenjaya Clinic, 2-13-2 Taishido, Setagaya-ku, Tokyo 154-0004, Japan.

Received: 28 August 2017 Accepted: 27 November 2017

Published online: 06 December 2017

\section{References}

1. Tonelli M, Wiebe N, Culleton B, et al. Chronic kidney disease and mortality risk: a systematic review. J Am Soc Nephrol. 2006;17:2034-47.

2. Alexiadis G, Panagoutsos S, Roumeliotis S, Stibiris I, Markos A, Kantartzi K, et al. Comparison of multiple fluid status assessment methods in patients on chronic hemodialysis. Int Urol Nephrol. 2017;49:525-32.

3. Lichtenstein D. Pneumothorax and introduction to ultrasound signs in the lung. In: Heilmann U, Wilbertz H, Gosling A, editors. General ultrasound in the critically ill. 1st ed. Heidelberg: Springer-Verlag; 2005. p. 105-15.

4. Agricola E, Bove T, Oppizzi M, Marino G, Zangrillo A, Margonato A, et al. "Ultrasound comet-tail images": a marker of pulmonary edema: a comparative study with wedge pressure and extravascular lung water. Chest. 2005;127:1690-5.

5. Kajimoto K, Madeen K, Nakayama T, Tsudo H, Kuroda T, Abe T. Rapid evaluation by lung-cardiac-inferior vena cava (LCI) integrated ultrasound for differentiating heart failure from pulmonary disease as the cause of acute dyspnea in the emergency setting. Cardiovasc Ultrasound. 2012;10:49-51. 
6. Kuzuhara S, Otsubo S, Kajimoto K, Akiba T, Nitta K. Association between Blines detected during lung ultrasound and various factors in hemodialysis patients. Ren Replace Ther. 2017;3:17.

7. Noble VE, Murray AF, Capp R, Sylvia-Reardon MH, Steele DJ, Liteplo A. Ultrasound assessment for extravascular lung water in patients undergoing hemodialysis: time course for resolution. Chest. 2009;135:1433-9.

8. Simonson JS, Schiller NB. Sonospirometry: a new method for noninvasive estimation of mean right atrial pressure based on two-dimensional echographic measurements of the inferior vena cava during measured inspiration. J Am Coll Cardiol. 1988;11:557-64.

9. Triulzi MO, Castini D, Ornaghi M, Vitolo E. Effects of preload reduction on mitral flow velocity pattern in normal subjects. Am J Cardiol. 1990; 66:995-1001.

10. Sztajzel J, Ruedin P, Monin C, Stoermann C, Leski M, Rutishauser W, et al. Effect of altered loading conditions during haemodialysis on left ventricular filling pattern. Eur Heart J. 1993;14:655-61.

11. Cardim N, Fernandez Golfin C, Ferreira D, Aubele A, Toste J, Cobos MA, et al. Usefulness of a new miniaturized echocardiographic system in outpatient cardiology consultations as an extension of physical examination. J Am Soc Echocardiogr. 2011;24:117-24.

12. Liebo MJ, Israel RL, Lillie EO, Smith MR, Rubenson DS, Topol EJ. Is pocket mobile echocardiography the next-generation stethoscope? A crosssectional comparison of rapidly acquired images with standard transthoracic echocardiography. Ann Intern Med. 2011;155:33-8.

13. Volpicelli G, Elbarbary M, Blaivas M, Lichtenstein DA, Mathis G, Kirkpatrick AW, et al. International liaison committee on lung ultrasound (ILC-LUS) for international consensus conference on lung ultrasound (ICC-LUS). International evidence-based recommendations for point-of-care lung ultrasound. Intensive Care Med. 2012;38:577-91.

14. Zoccali C. Lung ultrasound in the management of fluid volume in dialysis patients: potential usefulness. Semin Dial. 2017;30:6-9.

15. Picano E, Pellikka PA. Ultrasound of extravascular lung water: a new standard for pulmonary congestion. Eur Heart J. 2016;37:2097-104.

16. Acharya P, Ranabhat K, Trikhatri Y, Manandhar DN, Sharma SK, Karki P. Effect of preload reduction by haemodialysis on doppler indices of diastolic function in patients with end-stage renal disease. Kathmandu Univ Med J (KUMJ). 2008:6:98-101.

17. Feissel M, Michard F, Faller JP, Teboul JL. The respiratory variation in inferior vena cava diameter as a guide to fluid therapy. Intensive Care Med. 2004;30:1834-7.

18. Brennan JM, Ronan A, Goonewardena S, Blair JE, Hammes M, Shah D, et al. Handcarried ultrasound measurement of the inferior vena cava for assessment of intravascular volume status in the outpatient hemodialysis clinic. Clin J Am Soc Nephrol. 2006;1:749-53.

19. Mallamaci F, Benedetto FA, Tripepi R, Rastelli S, Castellino P, Tripepi G, et al. Detection of pulmonary congestion by chest ultrasound in dialysis patients. JACC Cardiovasc Imaging. 2010;3:586-94.

20. Katzarski KS, Nisell J, Randmaa I, Danielsson A, Freyschuss U, Bergstrom J. A critical evaluation of ultrasound measurement of inferior vena cava diameter in assessing dry weight in normotensive and hypertensive hemodialysis patients. Am J Kidney Dis. 1997;30:459-65.

21. Kouw PM, Kooman JP, Cheriex EC, Olthof CG, de Vries PM, Leunissen KM. Assessment of postdialysis dry weight: a comparison of techniques. J Am Soc Nephrol. 1993;4:98-104.

\section{Submit your next manuscript to BioMed Central and we will help you at every step:}

- We accept pre-submission inquiries

- Our selector tool helps you to find the most relevant journal

- We provide round the clock customer support

- Convenient online submission

- Thorough peer review

- Inclusion in PubMed and all major indexing services

- Maximum visibility for your research

Submit your manuscript at www.biomedcentral.com/submit

Biomed Central 